WellBeing International

WBI Studies Repository

$6-2003$

\title{
Habitat-Predator Association and Avoidance in Rainbowfish (Melanotaenia spp.)
}

Culum Brown

University of Queensland

Follow this and additional works at: https://www.wellbeingintlstudiesrepository.org/acwp_asie

Part of the Animal Studies Commons, Behavior and Ethology Commons, and the Comparative Psychology Commons

\section{Recommended Citation}

Brown, C. (2003). Habitat-predator association and avoidance in rainbowfish (Melanotaenia spp.).

Ecology of Freshwater Fish, 12(2), 118-126.

This material is brought to you for free and open access by WellBeing International. It has been accepted for inclusion by an authorized administrator of the WBI Studies Repository. For more information, please contact wbisr-info@wellbeingintl.org.

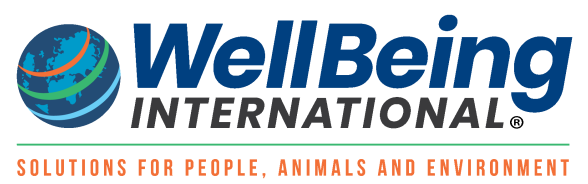




\title{
Habitat-Predator Association and Avoidance in Rainbowfish (Melanotaenia spp.)
}

\author{
Culum Brown \\ University of Queensland
}

\section{KEYWORDS}

predator avoidance, rainbowfish, ecology, cue use, habitat

\begin{abstract}
The ability to recall the location of a predator and later avoid it was tested in nine populations of rainbowfish (Melanotaenia spp.), representing three species from a variety of environments. Following the introduction of a model predator into a particular microhabitat, the model was removed, the arena rotated and the distribution of the fish recorded again. In this manner it could be determined what cues the fish relied on in order to recall the previous location of the predator model. Fish from all populations but one (Dirran Creek) were capable of avoiding the predator by remembering either the location and/or the microhabitat in which the predator was recently observed. Reliance on different types of visual cues appears to vary between populations but the reason for this variation remains elusive. Of the ecological variables tested (flow variability, predator density and habitat complexity), only the level of predation appeared to be correlated with the orientation technique employed by each population. There was no effect of species identity, which suggests that the habitat that each population occupies plays a strong role in the development of both predator avoidance responses and the cues used to track predators in the wild.
\end{abstract}

\section{Introduction}

Prey often face predators that can be found in certain areas (e.g. particular microhabitats) and/or at certain times of the day (Reebs 2000). Many piscivorous fish species are often found in particular microhabitats. Mary River cod (Maccullochella peelii mariensis Rowland), for example, often occupy the same snag (i.e. fallen timber) that they defend rigorously and return to even after lengthy migrations (Simpson \& Mapleston 2002). Mouth almighty (Glossamia aprion), major predators of rainbowfish, are always found in areas that are structurally complex, especially among dense weed beds (Hattori \& Warburton 2002). One would expect, therefore, that prey species would avoid specific locations and/or microhabitats commonly occupied by predators in order to reduce the risk of encountering them. Minnows (Pimephales promelas) learn to associate alarm substances with high-risk habitats and later avoid such areas, even when the alarm substance or predator odour is no longer present (Chivers \& Smith 1994, 1995). Chivers \& Smith suggest that, in clear, flowing water, fish probably rely heavily on vision to identify dangerous habitats. Similarly, Huntingford \& Wright (1989) showed that sticklebacks (Gasterosteus aculeatus) are capable of avoiding foraging patches associated with elevated predation risk, and that the 
ability to learn varies between populations, perhaps due to the level of predation risk experienced in their site of origin (Magurran 1990).

There is now a great deal of literature regarding how animals locate objects within their environment (for reviews see Gallistel 1990 and Healy 1998). In laboratory experiments fish appear to use one of the three methods to navigate through the test environment. Individuals may use specific location markers (local cues), remember the spatial relationship between a number of cues indicating the whereabouts of a particular location (global cues) or rely on a sequence of turns (algorithms) in order to reach their goal (Hughes \& Blight 1999).

The ways in which an animal's ecology influences the orientation skills of individuals have only recently begun to receive the level of attention they deserve (e.g. Giraldeau 1997; Dukas 1998). A number of navigation techniques may be employed depending on the past history of the animal and the nature of the spatial problems it commonly faces (Braithwaite et al. 1996). We may expect that the environment in which animals develop may strongly affect the types of cues that are used for orientation (Girvan \& Braithwaite 1998). It is conceivable that the types of cues used for orientation and navigation will depend on the level of stability in the environment (Girvan \& Braithwaite 1998). Environmental stochasticity may affect cue reliability. Girvan \& Braithwaite (1998) found that sticklebacks from different locations (lake and river populations) relied on different cues to learn the location of a foraging patch. Warburton (1990) suggested that reliance on local landmarks for orientation may also vary according to the nature and complexity of the visual environment. Fish derived from structurally complex environments may not rely on local landmarks since cues would be lost amongst the visual clutter.

This study attempted to address several questions regarding population variation in the avoidance of dangerous locations and microhabitats in rainbowfish (Melanotaenia spp.). Much is known about population variation in predator recognition and avoidance in rainbowfish already (Brown \& Warburton 1997, 1999). The four specific questions I wished to be addressed here are: (i) Can rainbowfish associate the presence of a predator with a particular location or microhabitat and subsequently avoid them? (ii) Is the ability to avoid dangerous areas related to the predation pressure at the site of collection? (iii) Do the various populations rely on different spatial cues to recall the whereabouts of predators and subsequently avoid dangerous microhabitats or locations or both? (iv) Is cue use related to the habitat variables at the site of collection (flow variability, habitat complexity and predator abundance)?

\section{Methods}

Three species of rainbowfish were chosen for this study: Melanotaenia eachamensis, $M$. splendida and M. spp. nov. (Utchee type; see McGuigan et al. 2000 for species details). Three populations originating from slightly different environments (Table 1 ) were collected for each species from eight locations in the Atherton and region of Northern Queensland (see Fig. 1 for a map of the sampling localities). A captive population of the Lake Eacham rainbowfish, which had been maintained in the laboratory, was also included in the experiment. The wild fish were air freighted to the University of Queensland, and all fish were held in holding tanks measuring $60 \mathrm{~cm} \times 35 \mathrm{~cm} \times 40 \mathrm{~cm}$. Each tank contained approximately 40 fish, and the water was filtered via under-gravel filters. Light conditions were $12 \mathrm{~L}: 12 \mathrm{D}$, temperature was maintained at $24^{\circ} \mathrm{C}$ and $\mathrm{pH}$ was close to neutral. All fish had adjusted to captive conditions for a month prior to the experiments, and readily accepted flake food. Only female fish were used during this experiment because they form the basis of many shoals and exhibit a relatively low amount of interindividual aggression. 
Table 1. A list of the populations used in this study, their species identity and habitat information.

\begin{tabular}{|c|c|c|c|c|}
\hline Species & Population & Flow variability & Predator pressure & Habitat complexity \\
\hline M. eachamensis & Lake Eacham captive stock & Low & Low & Low \\
\hline M. eachamensis & Dirran Creek & Moderate & Low & High \\
\hline M. eachamensis & Upper South Johnstone (USJ) & Low & Low & Moderate \\
\hline M. splendida & Upper North Johnstone (UNJ) & Moderate & Moderate & High \\
\hline M. splendida & Lower South Johnstone (LSJ) & Low & High & Low \\
\hline M. splendida & Ithica River & Moderate & Moderate & Moderate \\
\hline Utchee type & Short Creek & High & Low & High \\
\hline Utchee type & Utchee Creek & Moderate & Moderate & High \\
\hline Utchee type & Fishes Creek & High & High & Moderate \\
\hline \multicolumn{5}{|c|}{$\begin{array}{l}\text { Flow variability was calculated from the size of the catchment upstream of the collection site. The level of predation } \\
\text { pressure was calculated both from visual observation and from survey data, and represents the abundance of } \\
\text { potential piscivorous predators at each location. Habitat complexity represents a summary score for } 10 \text { habitat } \\
\text { variables. See Methods section for further details. }\end{array}$} \\
\hline
\end{tabular}

Habitat variables

At each locality, site descriptions were filled out which included information on land use, habitat complexity/availability, water quality and the level of disturbance (see Pusey \& Kennard 1994 and Pusey et al. $2000 \mathrm{~b}$ for further details). From this information relative levels of habitat complexity were calculated by adding up the total amount of refuge available for the fish at each site. A combination of 10 refuge types including the amount of overhanging vegetation, in-stream vegetation, overhanging banks, substrate type, substrate leaf litter, fallen timbers, etc. were scaled from 1 to 3,3 being most abundant. The refuge scores were summed. Sites with totals between 0 and 10 were allocated as low habitat structural complexity, scores between 10 and 20 were defined as intermediate habitat complexity and scores between 20 and 30 were defined as highly complex. Predator density information was gained from a combination of seine netting, visual observation (including snorkelling) and personal communication with Dr Brad Pusey, Griffith University, Brisbane, Australia. Pusey and colleagues have conducted several in-depth fish fauna surveys in the region and performed gut contents analyses on rainbowfish and their predators (Pusey et al. 1995a,b; Pusey \& Kennard 1996; Pusey et al. 2000a).

Stream flow data from six sites within the North and South Johnstone Rivers were obtained from The Department of Natural Resources, Queensland, Australia. The locations selected had between 30 and 80 years of flow data. Since flow variability (measured by the monthly standard variation about the mean annual flow rate) is highly correlated with catchment size $\left(R^{2}=0.811 ; n=6 ; P<0.001\right)$ and stream flow information was not available for every collection site, a flow variability index was estimated for each collection site by calculating the catchment area upstream of the collection sites. Sites with catchment areas over $120 \mathrm{~km}^{2}$ upstream were considered to have low flow variability (as was the captive stock originally from Lake Eacham). Sites with catchment areas between 20 and $100 \mathrm{~km}^{2}$ upstream were 
considered to have moderate flow variability. Sites with catchment areas under $20 \mathrm{~km}^{2}$ upstream were considered to have high flow variability. See Table 1 for a summary of the habitat variables for each site.

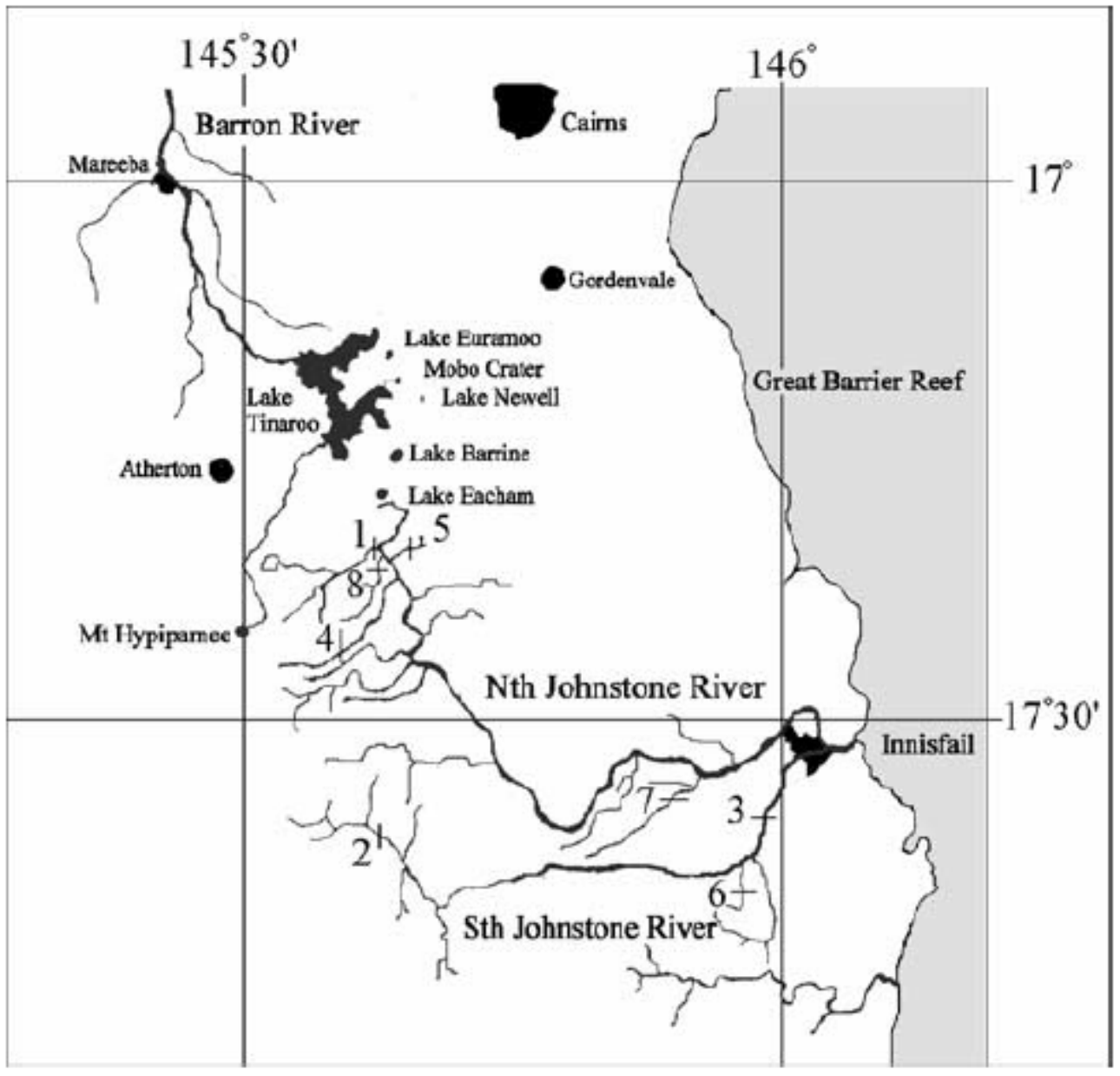

Fig. 1. The site locations of the populations examined: 1, upper North Johnstone River; 2, upper South Johnstone River; 3, lower South Johnstone River; 4, Dirran Creek; 5, Short Creek; 6, Utchee Creek; 7, Fisher Creek and 8, Ithica River. Lake Eacham is also marked on the map.

\section{Experimental apparatus}

A large experimental tank $(95 \mathrm{~cm} \times 95 \mathrm{~cm})$ was divided into four quadrants each containing a different habitat type. All sides of the tank were lined with white perspex and the bottom rested on white polystyrene. One quadrant contained fine branches made from plastic straws (snag), one contained artificial submerged aquatic weed (plastic strips of garbage bags attached to a plastic mesh), another contained river rocks (cleaned and washed prior to use) and the last contained no structure. The quadrants were numbered from 1 to 4 and allocated a habitat type based on a predetermined table. This eliminated any possible habitat-location bias. Water depth was maintained at $25 \mathrm{~cm}$ and at a temperature of $24^{\circ} \mathrm{C}$. The tank was surrounded by white cloth on three sides and across the roof. The fourth side was a white wall to which a camera was anchored to an arm that extended over the top of the tank. Four 
fluorescent tubes provided the lighting directly overhead. The light was diffused through the cloth to provide even light conditions within the entire enclosure.

\section{Experimental protocol}

Groups of five fish were selected at random from the holding tanks and placed into the experimental arena. The fish were allowed 20 min to settle into the new environment before recoding began. For a period of $75 \mathrm{~min}$, the locations of each fish was noted every $5 \mathrm{~min}$. At the end of that time the preferred habitat type was determined and a model predator placed into that quadrant.

A predator model (see Brown \& Warburton 1997 for details of the model) of a mouth almighty, Glossamia aprion, was attached to an overhead system of pulleys and elastic that allowed the observer to move the model towards any fish entering the preferred habitat. The model was introduced for 30min during which the behavior and location of the fish was recorded. The model was then removed and the tank rotated $90^{\circ}$ in order to control for the possibility that the fish were relying on global cues (multiple cues lying outside the arena, for example the camera anchor) rather than avoiding the microhabitat (local cues) containing the predator. Following rotation of the experimental tank, the fish were allowed to settle for a further 10 min, and their location was then recorded for another 75-min period. The procedure was repeated eight times per population, thus a total of 40 fish were used per population.

The proportion of time the fish spent in each habitat was recorded for the periods 'before', 'during' and 'after' the presentation of the model predator. The amount of time spent in the preferred habitat during exposure to the model and following the removal of the model and rotation of the tank was expressed as a proportion of the time spent in the preferred habitat before the fish were exposed to the model predator (i.e. during/before $\times 100$, after/before $\times 100$ for the periods 'during' and 'after', respectively). Data were arc-sine transformed and analysed independently for an effect of species identity, population, predator pressure, habitat complexity and stream flow variability using repeated measures analysis of variance.

\section{Results}

The results of the repeated measures tests suggested that there was no effect of species identity, the level of habitat complexity, flow variability or predation pressure at the collection sites on the tendency of the fish to avoid the dangerous microhabitat (Table 2a) or location (i.e. using global cues; Table 3a) which was contained with the predator model prior to the rotation of the experimental tank. In all cases, however, there was a highly significant time effect $(P<0.0001)$ primarily due to the large decrease in occupation of the preferred habitat while the predator was present (Fig. 2). Most of the populations avoided the 'dangerous' microhabitat, with the exception of the Dirran Creek fish and fish from both the upper and lower South Johnstone River (although the latter two were marginal; $P<0.06$; Table 2b). It should be noted that the lower South Johnstone fish showed a very strong avoidance response while the predator was present but rapidly reoccupied the preferred habitat once the predator was removed (Fig. 2). Fishers, Ithica, Lower South Johnstone and Utchee also avoided the location that the model occupied prior to rotation (Table $3 b$ ). All of these populations are exposed to high or moderate levels of predation pressure (Table 1). These results suggest that these latter populations were relying on global cues as well as local cues to avoid both the high-risk location and microhabitat.

It is clear that the introduction of the predator to the initially preferred habitat/quadrant caused a significant decline in the occupancy of this habitat/quadrant in most populations (Fig. 2). Dirran Creek, Short Creek and upper South Johnstone River fish by contrast did not show a change in habitat occupancy (Table 4b). All three of these populations contain very few predators in the wild (Table 1). Generally, the strength of the avoidance response increased with the level of predation pressure at the 
collection sites. If data from moderate and high predator populations are combined we find significant differences compared with fish from low predator regimes (d.f. $=1 ; F=4.623 ; P=0.035$; Fig. 3). Interestingly, there was also a week negative relationship between the avoidance response and the level of habitat complexity at the collection sites. However, this effect may be due to the correlation between habitat variables. Following removal of the predator model and rotation of the tank, a general trend to move back into the preferred habitat and quadrant is evident (Fig. 2).

Table 2a. The results of a repeated measures ANOVA analysis of microhabitat avoidance following the removal of the model and rotation of the experimental tank.

\begin{tabular}{|lccc|}
\hline Effect & d.f. & F-value & $P$-value \\
\hline Population & 8 & 0.456 & 0.882 \\
Species & 2 & 0.168 & 0.846 \\
Predators & 2 & 0.220 & 0.803 \\
Habitat complexity & 2 & 0.409 & 0.666 \\
Flow variability & 2 & 0.081 & 0.922 \\
\hline $\begin{array}{l}\text { In all cases P <0.0001 for the time effect reflecting a strong change in the level of occupancy of the preferred habitat } \\
\text { following the introduction and subsequent removal of the predator model. None of the habitat variable adequately } \\
\text { account for the avoidance responses shown by the fish. }\end{array}$ \\
\hline
\end{tabular}

Table $2 \mathrm{~b}$. A summary of a repeated measures ANOVA analysis of microhabitat avoidance by population following the removal of the model and rotation of the experimental tank.

\begin{tabular}{|llll|}
\hline Population & d.f. & F-ratio & $P$-value \\
\hline Upper North Johnstone & 7 & 27.565 & 0.0012 \\
Captive & 7 & 11.442 & 0.0117 \\
Dirran & 7 & 2.911 & 0.1317 \\
Fishers & 7 & 10.729 & 0.0136 \\
Ithica & 7 & 7.225 & 0.0312 \\
Lower South Johnstone & 7 & 5.409 & 0.0529 \\
Short & 7 & 12.597 & 0.0094 \\
Upper South Jonstone & 7 & 5.439 & 0.0525 \\
Utchee & 7 & 20.706 & 0.0026 \\
\hline $\begin{array}{l}\text { Dirran Creek showed the poorest avoidance of the preferred habitat following the introduction of the model. Both } \\
\text { lower and upper South Johnstone fish showed statistically marginal avoidance whilst the remaining populations all } \\
\text { showed strong avoidance of the habitat that once contained the predator model. }\end{array}$ \\
\hline
\end{tabular}


Table 3a. The results of a repeated measures ANOVA analysis of quadrant avoidance following the removal of the model and rotation of the experimental tank.

\begin{tabular}{|lllc|}
\hline Effect & d.f. & F-ratio & $P$-value \\
\hline Population & 8 & 0.147 & 0.997 \\
Species & 2 & 0.399 & 0.673 \\
Predators & 2 & 0.521 & 0.596 \\
Habitat complexity & 2 & 0.014 & 0.986 \\
Flow variability & 2 & 0.039 & 0.962 \\
\hline $\begin{array}{l}\text { In all cases P }<0.0001 \text { for the time effect. None of the habitat variable adequately account for the avoidance of the } \\
\text { location of the model shown by the fish. }\end{array}$ &
\end{tabular}

Table 3b. A summary of a repeated measures ANOVA analysis of quadrant avoidance by population following the removal of the model and rotation of the experimental tank.

\begin{tabular}{|l|c|c|c|}
\hline Population & d.f. & F-ratio & P-value \\
\hline Upper North Johnstone & 7 & 2.308 & 0.1725 \\
\hline Captive & 7 & 3.871 & 0.1563 \\
\hline Dirran & 7 & 20.396 & 0.0898 \\
\hline Fishers & 7 & 6.868 & 0.0344 \\
\hline Ithica & 7 & 47.560 & 0.0002 \\
\hline Lower South Johnstone & 7 & 3.195 & 0.1170 \\
\hline Short & 7 & 2.984 & 0.1277 \\
\hline Upper South Jonstone & 7 & 6.593 & 0.0371 \\
\hline Utchee & 7 & & \\
\hline $\begin{array}{l}\text { Four of populations showed statistically significant avoidance of the location of the predator. The remaining } \\
\text { populations showed only a slight avoidance of the location of the model. }\end{array}$
\end{tabular}




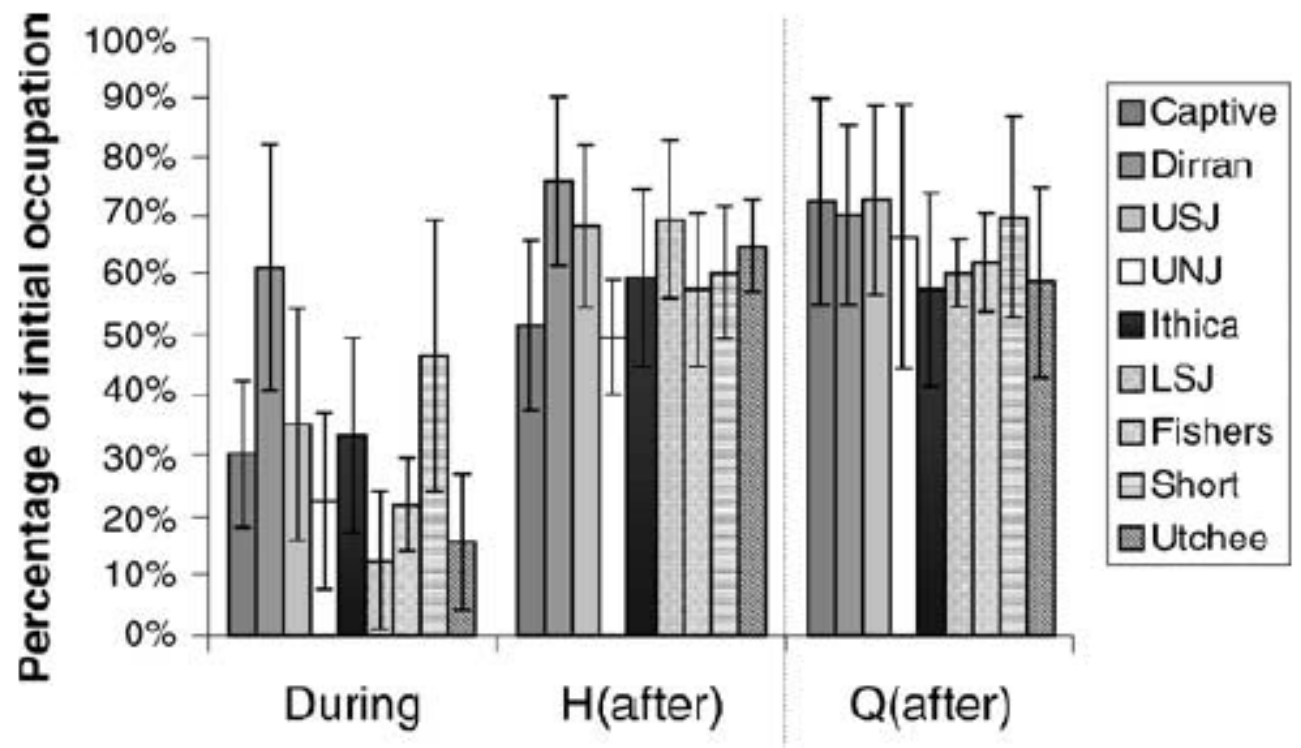

Fig. 2. The amount of time spent in various quadrants relative to the amount of time spent in the preferred microhabitat before the introduction of the predator model. The amount of time spent in the preferred habitat before the introduction of the predator is equal to $100 \%$. 'During' refers to the amount of time spent in the habitat containing the predator model during exposure. ' $\mathrm{H}$ (after)' and ' $\mathrm{Q}$ (after)' refer to the proportion of time spent in the microhabitat and quadrant (location) that contained the model prior to its removal and the rotation of the experimental arena. Fish using global cues should avoid the location that previously contained the threat. Fish utilising local cues should avoid the microhabitat that contained the threat. Error bars represent standard error. The first three populations listed are Melanotaenia eachamensis, the second three $M$. splendida and the final three are the Utchee-type rainbowfish.

Table 4a. The results of a repeated measures analysis of predator avoidance as defined by the change in occupancy of the preferred habitat during the presence of the predator model.

\begin{tabular}{|llcc|}
\hline Effect & d.f. & F-ratio & $P$-value \\
\hline Population & 8 & 0.962 & 0.473 \\
Species & 2 & 1.232 & 0.298 \\
Predators & 2 & 2.396 & 0.098 \\
Habitat complexity & 2 & 1.064 & 0.351 \\
Flow variability & 2 & 0.144 & 0.866 \\
\hline Only the level of predation pressure at the sites explained come of the variability on the data. & \\
\hline
\end{tabular}


Table 4b. A summary of a repeated measures analysis of predator avoidance by each population as defined by the change in occupancy of the preferred habitat during the presence of the predator model.

\begin{tabular}{|l|c|c|c|}
\hline Population & d.f. & F-ratio & P-value \\
\hline Upper North Johnstone & 7 & 27.756 & 0.0012 \\
\hline Captive & 7 & 32.329 & 0.0007 \\
\hline Dirran & 7 & $\mathbf{3 . 5 2 8}$ & $<0.0001$ \\
\hline Fishers & 7 & 102.520 & 0.0046 \\
\hline Ithica & 7 & $\mathbf{1 6 . 7 5 7}$ & $\mathbf{0 . 0 0 0 1}$ \\
\hline Lower South Johnstone & 7 & $\mathbf{5 . 4 4 7}$ & $\mathbf{0 . 0 5 2 3}$ \\
\hline Short & 7 & $\mathbf{1 1 . 1 8 5}$ & $\mathbf{0 . 0 1 2 3}$ \\
\hline Upper South Jonstone & 7 & $\mathbf{5 4 . 5 3 2}$ & $\mathbf{0 . 0 0 0 2}$ \\
\hline Utchee & 7 & & \\
\hline $\begin{array}{l}\text { All populations showed strong avoidance of the predator model with the exception of Dirran Creek fish. Fish from } \\
\text { Short Creek showed a statistically marginal avoidance response. }\end{array}$
\end{tabular}

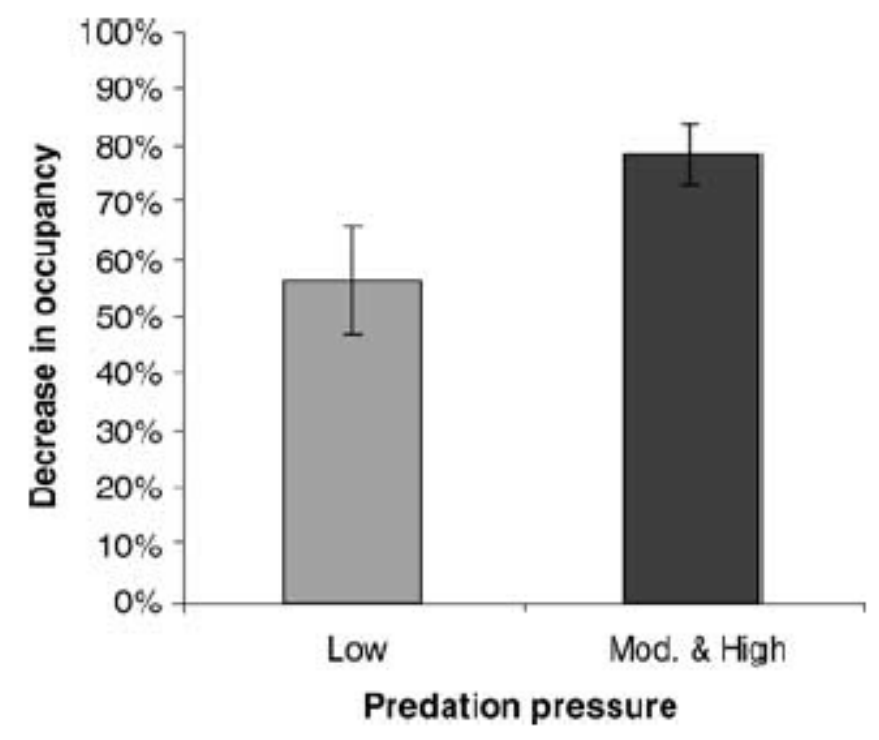

Fig. 3. The relative decrease in occupancy of the preferred habitat following the introduction of the model predator. Data have been lumped for fish collected from sites with high and moderate levels of predation. Error bars represent standard error. 


\section{Discussion}

Strong avoidance of dangerous habitats has been reported previously in sticklebacks (Huntingford \& Wright 1989) and galaxiids (Reebs 2000), and appears to be a common ability among many rainbowfish populations. Rainbowfish from all but three test populations were capable of using visual cues to associate predators with either the location (global cues) or the microhabitat (local cues) that the predator was last encountered in. One of these three was the Dirran Creek population. The Dirran Creek fish did not avoid the habitat the predator was located in, even with the presence of the predator model. This poor avoidance response by Dirran Creek fish has been reported previously (Brown \& Warburton 1997), and may stem from long-term isolation from predators. Dirran Creek has a long series of rapids and waterfalls before flowing into the North Johnstone River that would act as a substantial barrier to large predatory fish species. The other populations that showed poor avoidance behaviour were the upper and lower South Johnstone fish. Like the Dirran Creek fish, the upper South Johnstone fish also have virtually no piscivorous predators; however, their lack of avoidance of the dangerous habitat was only marginally insignificant $(P=0.053$; Table $2 \mathrm{~b})$. These fish showed a strong avoidance response while the predator was present but quickly reoccupied their preferred habitat once the threat had been removed. The lower South Johnstone fish showed a similar marginal avoidance of the dangerous microhabitat following the removal of the predator ( $P=0.053$; Table $2 b$ ), but strongly avoided the microhabitat containing the predator model while it was present (Fig. 2).

There was a strong overall trend towards increasing avoidance of the dangerous habitat as the level of predation threat experienced at each site increased. By combining the high and moderate predator populations a significant effect of predation level on habitat avoidance emerges. These data may be explained in two ways. Firstly, predator-naïve populations may show poor avoidance responses while the predator is present and barely alter their use of the preferred habitat at all (e.g. Dirran and Short Creek). Secondly, predator-naïve fish may also reoccupy the dangerous habitat very quickly, once the disturbance is removed (e.g. the captive Lake Eacham and upper South Johnstone populations). This latter response on it's own, however, is not necessarily indicative of predator regimes since many of the other populations show similar rates of reoccupation (e.g. lower South Johnstone River).

The initial avoidance response displayed by populations from areas containing low predation pressure while the predator was present in the arena was significantly less than that of populations from sites with both high and moderate predation pressure. This suggests a fundamental difference in the antipredator behaviours displayed by populations that are relatively predator naïve compared with predator-wary populations. Population differences arising from site-specific differences in predation pressure are common amongst many fish species (guppies, minnows, sticklebacks, etc.), and has been observed in other species of rainbowfish in previous experiments (Brown \& Warburton 1997, 1999)

Four of the nine populations also showed significant avoidance of the location housing the model, following its removal and rotation of the experimental arena, indicating the use of global (or extra maze) cues. These populations all came from areas with moderate and high levels of predation. Fish from three populations avoided both the habitat and the quadrant indicating that they relied on both global and local cues to avoid the location of the predator (i.e. they avoided both the location and microhabitat). These populations were the only populations that lived sympatrically with sooty grunter (Hephaestus sp.), a highly mobile predator. It may be that fish from areas containing large numbers of mobile predators cannot rely on a single cue type alone to track predators, and must remember both the location and the type of microhabitat within which the predators were last observed.

Many of the fish gradually moved back into the microhabitat or quadrant that contained the predator, once it had been removed. Fish from Ithica, Fishers and Utchee Creek, in particular, showed the greatest 
reoccupation rate following the removal of the predator. All three creeks are relatively small and had moderate-to-high levels of predation pressure, flow variability and habitat complexity. In these streams it may be fairly costly to avoid a location for extended periods especially if the location of predators and prey items is temporally and/or spatially unpredictable. It may, under theses circumstances, pay to take a risk in order to gain access to foraging opportunities, particularly for rainbowfish, which rely on drifting invertebrates as a primary food source.

Unlike previous studies, the data presented here suggest that reliance on various cue types does not vary significantly with habitat stability as proposed by Girvan \& Braithwaite (1998). Nor was there strong evidence to suggest that the level of habitat complexity played a role in cue reliance (cf. Warburton 1990). However, the data do suggest that local landmarks (i.e. specific aspects of microhabitat structure) were utilised more often than global cues (i.e. cues indicating the general location) in orientation behaviour by most rainbowfish populations. At this stage it remains unclear why some populations rely on global cues while others rely on local cues or a combination of the two, although predator regimes may go some of the way in explaining these differences.

Perhaps one confounding problem with this experiment is the relationship between the habitat variables examined. Predators were typically found in the lower reaches of the tributaries. These areas are also characterised by low water-flow variability and low habitat complexity. The reverse is true of the upper reaches. While nearly all of the populations contained a unique combination of the three habitat variables tested, it would require a great many more sample sites to rigorously investigate all of the possible permutations.

One thing that all test populations do have in common is that they live in relatively clear water. Studies conducted by Warburton (1990) suggest that goldfish (Carassius auratus) relied on cues outside the experimental tank to aid in forage patch orientation. It is possible that the fish used the arm of the camera as an external cue during this experiment and possibly daylight from the windows along one side of the room. Sticklebacks (Gaterosteus aculeatus) and goldfish have also been shown to use a variety of cues for orientation (Girvan \& Braithwaite 1998; Lopez et al. 1999). Recalling the location of a particular object is much easier (cognitively speaking) if it can be associated with a single local cue or beacon (e.g. a particular microhabitat) rather computation based on the relationship between multiple global cues (Zanforlin 1990). Therefore, we would expect the majority of rainbowfish to utilise local cues preferentially, and subsequently only avoid the dangerous microhabitat. This is especially the case when the reliable global cues lie outside the experimental arena, many of which were deliberately eliminated. It may well be that only a small number of fish were aware of objects lying outside of the arena, and therefore utilised them for orientation. Perhaps in nature the relationship between global and local cues rarely contradict each other and individuals rely on a number of cues to navigate.

It is clear from this experiment that rainbowfish rely on visual cues for navigation but it is also likely that in the wild they would also use chemosensory cues associated with particular habitat types or localities. Chemo-sensory cues are widely used by other fish species (Huntingford \& Wright 1989; Halvorsen \& Stabell 1990), but were deliberately removed from this experiment. Future experiments could aim at establishing the relative importance of cue types in rainbowfish orientation since many animals use a hierarchy of cues for orientation, switching from one cue to another as the need arises (Able 1993).

In summary, most populations of rainbowfish tested were capable of avoiding dangerous habitats by remembering either the location and/or the microhabitat where a predator was last observed. Reliance on different types of cues appears to vary between populations but the reason for this variation remains elusive and does not appear to be related, at least in a simple way, to species identity, environmental variability or habitat complexity. The presence or absence of predators and perhaps even the identity of 
the predators at each location may explain some of the variation observed between populations. In many of the populations the avoidance of the dangerous habitat or location began to decay straight after the model predator was removed. Long-term avoidance probably requires constant negative reinforcement to offset potential foraging gains.

\section{Acknowledgements}

I shall like to thank all the people who helped collect rainbowfish from the Atherton Tablelands, Felicity Jones, Katrina McGuigan, Brad Pusey, Mark Kennard and others. I shall also like to thank my Ph.D. supervisor, Kevin Warburton, for his support. All of the work conducted in this experiment was done with the permission from the animal ethics committee of the University of Queensland.

\section{References}

Able, K.P. 1993. Orientation cues used by migratory birds: a review of cue conflict experiments. Trends in Ecology and Evolution 8: 367-371.

Braithwaite, V.A., Armstrong, J.D., McAdam, H.M. \& Huntigford, F.A. 1996. Can juvenile salmon use multiple cue systems in spatial learning? Animal Behaviour 51: 1409-1415.

Brown, C. \& Warburton, K. 1997. Predator recognition and anti-predator responses in the rainbowfish, Melanotaenia eachamensis. Behavioural Ecology and Sociobiology 41: 61-68.

Brown, C. \& Warburton, K. 1999. Differences in timidity and escape responses between predator-naïve and predator-sympatric rainbowfish populations. Ethology 105: 491-502.

Chivers, D.P. \& Smith, R.J.F. 1994. Flathead minnows (Pimephales promelas) learn to recognise chemical stimuli from high-risk habitats by the presence of alarm substance. Behavioural Ecology 6: $155-158$.

Chivers, D.P. \& Smith, R.J.F. 1995. Chemical recognition of risky habitats in cultural transmitted among flathead minnows, Pimephales promelas (Osteichthes, Cyprinidae). Ethology 99: 286-296.

Dukas, R. 1998. Cognitive ecology. Chicago: University of Chicago Press.

Gallistel, C.R. 1990. The organisation of learning. Cambridge: MIT Press.

Giraldeau, L.A. 1997. Ecology of information use. In: Krebs, J.R. \& Davies, N.B., eds. Behavioural ecology: an evolutionary approach, 4th edn. Oxford: Blackwells Scientific, pp. 42-68.

Girvan, J.R.\&Braithwaite, V.A. 1998. Population differences in spatial learning in three-spined sticklebacks. In: Proceedings of the Royal Society of London Series B. 265: 913-918.

Halvorsen, M. \& Stabell, O.B. 1990. Homing behaviour of displaced stream dwelling trout. Animal Behaviour 39: 1089-1097.

Hattori, A. \& Warburton, K. 2003. Microhabitat use by the rainbowfish, Melanotaenia duboulayi, in a subtropical Australian stream. Journal of Ethology 21: 15-22.

Healy, S.D. 1998. Spatial representations in animals. Oxford: Oxford University Press.

Hughes, R.N. \& Blight, C.M. 1999. Algorithmic behavior and spatial memory are used by two intertidal fish species to solve the radial maze. Animal Behaviour 58: 601-613.

Huntingford, F.A. \& Wright, P.J. 1989. How sticklebacks learn to avoid dangerous feeding patches. Behavioural Processes 19: 181-189.

Lopez, J.C., Broglio, C., Rodriguez, F., Thinus-Blanc, C. \& Salas, C. 1999. Multiple spatial learning strategies in goldfish (Carassius auratus). Animal Cognition 2: 109-120. 
Magurran, A.E. 1990. The inheritance and development of minnow anti-predator behaviour. Animal Behaviour 39: 834-842.

McGuigan, K., Zhu, D., Allen, G.R. \& Moritz, C. 2000. Phylogenetic relationships and historical biogeography of melanotaeniid fishes in Australia and New Guinea. Marine and Freshwater Research 51: 713-723.

Pusey, B.J., Arthington, A.H. \& Read, M.G. 1995a. Species richness and spatial variation in fish assemblage structure in two rivers of the wet tropics of northern Queensland, Australia. Environmental Biology of Fishes 42: 181-199.

Pusey, B.J., Arthington, A.H. \& Read, M.G. 2000a. The dry-season diet of freshwater fishes in monsoonal tropical rivers of Cape York Peninsula, Australia. Ecology of Freshwater Fish 9: 177-190.

Pusey, B.J. \& Kennard, M.J. 1994. The Freshwater Fish Fauna of the Wet Tropics Region of Northern Queensland. Internal Report for the Cooperative Research Centre for Tropical Rainforest Ecology and Management, Cairns, Australia.

Pusey, B.J. \& Kennard, M.J. 1996. Species richness and geographical variation in assemblage structure of the fresh-water fish fauna of the Wet Tropics region of northern Queensland. Marine and Freshwater Research 47: 563-573.

Pusey, B.J., Kennard, M.J. \& Arthington, A.H. 2000b. Discharge variability and the development of predictive models relating stream fish assemblage structure to habitat in. Northeastern Australia. Ecology of Freshwater Fish 9: 30-50.

Pusey, B.J., Read, M.G. \& Arthington, A.H. 1995b. The feeding ecology of fresh-water fishes in two rivers of the Australian wet tropics. Environmental Biology of Fishes 43: 85-103.

Reebs, S.G. 2000. Time-place learning based on food but not on predation risk in a fish, the inanga (Galaxias maculatus). Ethology 105: 361-371.

Simpson, R.R. \& Mapleston, A.J. 2002. Movements and habitat use by the endangered Australian freshwater Mary River cod, Maccullochella peelii mariensis. Environmental Biology of Fishes 65: 401-410.

Warburton, K. 1990. The use of local landmarks by foraging goldfish. Animal Behaviour 40: 500-505.

Zanforlin, M. 1990. Perception, learning and biological evolution. Ethology, Ecology and Evolution 2: 288290. 